\title{
Optimization of Electrode Material for EDM Die-sinking of Titanium Alloy Grade 5 - Ti6Al4V
}

\author{
Sangeeth Suresh", Muhammad Akmal Jamil ${ }^{\#}$, Shahidatunnajwa Sulaiman ${ }^{\#}$, Muhammad Rozani M.Shokor ${ }^{\#}$ \\ \# Institute of Product Design \& Manufacturing, Universiti Kuala Lumpur, Kuala Lumpur, 56100, Malaysia \\ E-mail:sangeeth@unikl.edu.my; muhammadakmaljamil@gmail.com; Najwa.sulaiman11@gmail.com; mrozani@unikl.edu.my
}

\begin{abstract}
Titanium alloy grade 5, Ti6Al4V, is extensively gaining importance in the industrial environment, specifically in aerospace, medical and automotive domains, mainly due to its exceptional blend of mechanical properties like high hardness which is further heat treatable, high strength-to-weight ratio which makes it light, high corrosion and temperature resistance etc. However, the same properties undervalue Ti6Al4V as a conventionally difficult-to-machine material. Rapid tool wear, excessive heat generation, dimensional instability and loss of surface integrity are the issues that plague the conventional machining of Ti6Al4V. In view of these facts, non-traditional machining processes like electron discharge machining (EDM) - die sinking and wire cut prove to be a substitute for the conventional machining. In this study, an experimental optimization of EDM die-sinking electrode materials among copper, brass and graphite, is carried out. Experimental design is created using a statistical tool and actual machining is carried out to record the surface roughness, variations on the surface hardness and dimensional stability. Quality evaluation and statistical analysis substantiates graphite electrodes to produce better surface finish-Ra 2.05 microns with minimal dimensional variation-less than $10 \%$ when operated at minimum spark gaps. It is inferred that graphite electrodes exhibit higher resistivity towards current than its counterparts thus passing minimum spark energy preventing excessive self-wear and a dimensionally accurate work piece. The depth of machining highly impacts the variations on the surface hardness post machining.
\end{abstract}

Keywords - Ti6Al4V; EDM die-sinking; spark gap; surface roughness; dimensional differential

\section{INTRODUCTION}

This Titanium alloys are widely being used in applications those require high fatigue strength, resistance to wear and corrosion, light weight and high hardness. Most of these properties are required in aerospace and automotive components, medical transplants, gas turbines, sports and recreational equipment and also other consumer goods [1, 2]. Ti6Al4V or Grade 5 is the most popular grade of titanium alloy occupying about $50 \%$ of the overall Ti alloy market consumption and is usually considered as the work horse among its various grades due to its extreme usage in the fields mentioned above [3]. Ti6Al4V is also a good thermal and electrical conductor. They are also one among the most difficult-to-machine metals due to its high hardness 280 380 brinnel hardness (HB). Researches have been carried out in the conventional machining of Ti6Al4V and various sets of machining parameters have been recommended by researchers. However due to its poor machinability, Ti6Al4V machining using traditional methods still poses a challenge Non-conventional machining is also an alternative for the machining of such difficult-to-machine metals. EDM sparking or die-sinking is a feasible alternative to machine complex profiles in Ti6Al4Vconsidering its hardness and also since it is an excellent conductor of electricity. An EDM Die sinking process as shown in Figure 1 uses an electrode (tool) which is shaped according to the profile required on the metal being machined

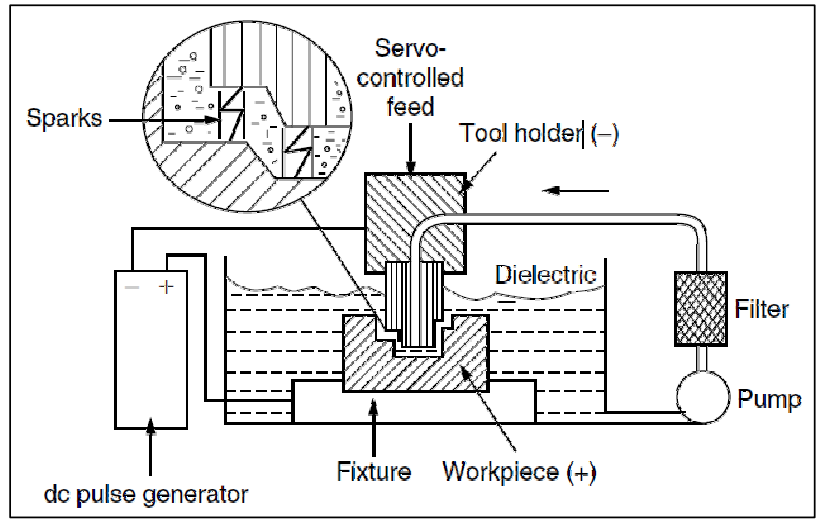

Fig. 1 Schematic of an EDM die sink process

[Pic.source: http://www.mechscience.com/4252-electrical-dischargemachining-process-electrical-discharge-machining-principle]

A deliberate voltage differential between the tool and the work piece creates an electric spark between them causing 
erosion in the metal thus shaping the metal. The whole process is either submerged in electrolyte or the electrolyte is flushed using hoses at the area being machined. Widely used electrode materials are copper, graphite, aluminium, brass, tungsten, copper impregnated graphite, copper alloys, etc. [4].

Previous researches on the EDM process of Ti6Al4V have reported on the efficiency of graphite electrodes over copper and aluminium electrodes, in terms of surface integrity and rate of material removal but give an adverse result in terms of surface finish [5]. It has been stated that the pulse current and pulse energy directly affects the surface integrity of Ti6Al4V work piece. Increase in pulse energy is directly proportional to the material removal rate but in turn creates a hardened thick layer on the surface being machined [6].

It has also been revealed that, though there isn't any substantial variation in the tensile strength of Ti6Al4V after EDM using graphite electrode, the process may still inversely affect its fatigue strength leading to an earlier failure. Hence effects on the fatigue strength have been found to be a limitation of the EDM process of Ti6Al4V which has been further attributed to the brittleness of the surface layer. It also is noted that in many cases EDM of Ti6Al4V is not only used for material removal but also for surface treatment [7].

This paper covers the effects of EDM process on Ti6Al4V work piece. It evaluates the surface roughness, hardness and also rate of surface wear on both the electrode and the metal. The comparison of the results is made between the usages of three different types of electrode materials namely copper, graphite and brass. Experiments are carried out with the electrode material, the spark gap and the depth of cut as the manipulators and the surface roughness, hardness and dimensional variations as the responses. Design of experiments is a proven tool for analyzing the interactions between the manipulated variables and their responses [8] and has been used here for similar analysis of the input data and the results of the experiments.

\section{METHODOLOGY}

Ti6Al4V blocks are used as the work piece and the EDM operation (non-orbital machining) is performed with three different electrode materials as mentioned above. Copper, graphite and brass rods are machined to $\varnothing 20.0 \mathrm{~mm}$ minus the spark gap and provided with an M6 thread for holding purposes. Spark gaps of $0.2,0.25$ and 0.3 per side are considered on the diameter of the electrodes for every material which means copper, graphite and brass have three electrodes each of $\varnothing 19.6 \mathrm{~mm}(0.2 \mathrm{~mm}$ spark gap/side), $\varnothing 19.5 \mathrm{~mm}(0.25 \mathrm{~mm}$ spark gap/side) and $\varnothing 19.4 \mathrm{~mm}(0.3 \mathrm{~mm}$ spark gap /side). The above arrangement is usually considered for finishing, semi-finishing and roughing operations respectively.

Ti6Al4V, as mentioned earlier is a material with high hardness and low thermal conductivity of $6.7 \mathrm{~W} / \mathrm{m}-\mathrm{k}$ which is about $60 \%$ less than the commercially pure titanium, combined with a very high melting point of $1620^{\circ} \mathrm{C}$ [9]. These three properties are determinants those influence the efficiency of an EDM process. More heat (thermal energy produced by the spark), which means a higher voltage, is required to erode $\mathrm{Ti} 6 \mathrm{Al} 4 \mathrm{~V}$, ultimately resulting in a faster erosion rate of the electrodes, all the three types - copper, brass and graphite, being softer when compared to Ti6Al4V work piece. Among the three brass has the lowest thermal conductivity-70W/m-k and melting point $-940^{\circ} \mathrm{C}$ and hence lesser will be the loss of heat during operation and a faster melting of the brass electrode will be observed.

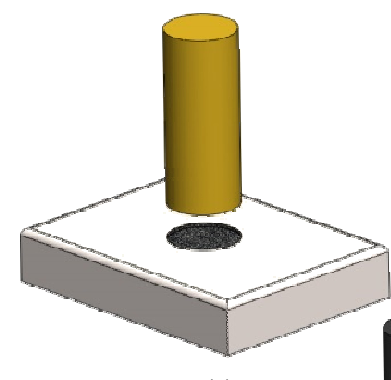

(a)

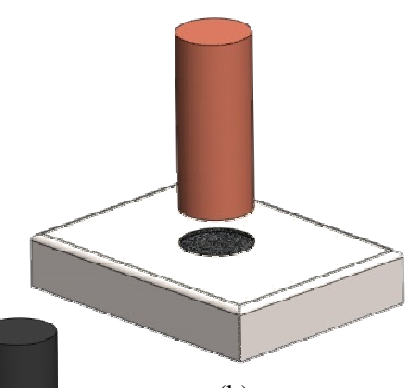

(b)

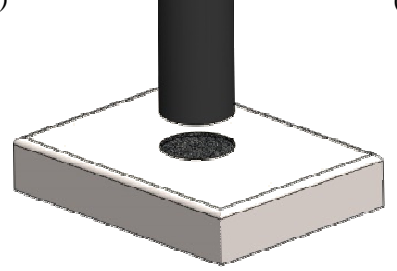

(c)

Fig. 2 EDM Process on titanium block using (a) copper electrode, (b) brass electrode, (c) graphite electrode

Though graphite has a thermal conductivity- 65 95W/m-k, very close to brass, the former's melting point $5530^{\circ} \mathrm{C}$ is extremely high leading to a slower rate of electrode wear. Copper has the highest heat transfer rate $231 \mathrm{~W} / \mathrm{m}-\mathrm{k}$ and a low melting point $-1080^{\circ} \mathrm{C}$ thus wearing off at a faster rate [10,11].

From the above stated facts, it could be hypothesized that in terms of material removal rate, Graphite electrodes would be more efficient in the electron discharge machining of Ti6Al4V followed by copper and brass in order. However, it is equally important to analyze the surface integrity and the surface hardness of the work piece after EDM as the quality of the work piece cannot be compromised over faster completion of the process. A Mitsubishi EA12DM Dyna Tech machine is used for the experiment with Castrol Ilocut EDM 401 oil (submerged with flushing) as the electrolyte. A transistor pulse (TP) power circuit method is adapted which is the most general-purpose circuit, as quoted by past researchers, to provide a higher material removal rate as the discharge energy is higher [12].

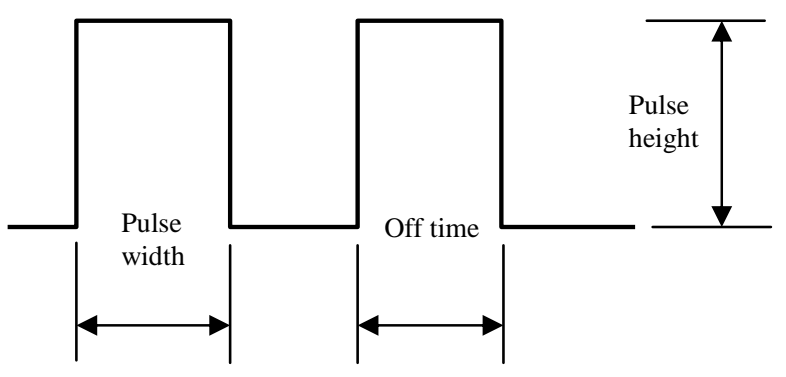

Fig. 3 Current pulse waveform 
The pulse height (current setting), the pulse width (the duration of the EDM spark measured in microseconds) and the off time (time between consecutive sparks measured in microseconds) are decided by the oscillation circuit that is selected. A TP circuit produces thousands of pulses/second which further produces shorter intervals between pulses (off time). The combination of these three factors widely determines the surface finish, material removal and surface hardness of the work [13].

A pre-set peak current (pulse height) of 50 Amps is set as Ti6Al4V is a high hardness material. More the hardness, greater current is required to produce greater spark energy to erode the material. The pulse width is set to $40 \mu \mathrm{s}$ (microseconds) and the off time is set to $30 \mu \mathrm{s}$. A servo mechanism controls the $\mathrm{Z}$ axis gap between the electrode and the work piece while a dimensional compensation on the electrode maintains the same gap along the $\mathrm{X} \& \mathrm{Y}$ axis.

The spark gap or arc gap is maintained to prevent arcing or burning of the sparked surface and also to achieve a desired surface finish. The spark gap also determines the speed of the operation. Larger the spark gap, rougher is the operation and material removal is greater and coarse. A smaller spark gap is maintained where a finer finish is required in turn taking a longer time [14].

\section{A. Experimental Design}

A three-factor, three-level $\left(3^{3}\right)$ experimental design is created, the factors being electrode material (EM), spark gap (SG) and depth of cut (DoC), in order to measure the responses namely surface roughness, surface hardness $(\mathrm{SH})$ an dimensional differential (DD). The dimensional differential is the difference between the intended depth and the actual depth that has been achieved after the process, measured in $\mathrm{mm}$ using a plunger dial depth gauge. Table I. lists down the different levels that have been assigned to the manipulated variables or the input factors.

TABLE I

INPUT FACTORS AND THEIR LEVELS

\begin{tabular}{|c|c|c|c|}
\hline Factors & $\begin{array}{l}\text { Electrode } \\
\text { Material }\end{array}$ & $\begin{array}{l}\text { Spark } \\
\text { Gap } \\
(\mathbf{m m} / \text { side) }\end{array}$ & $\begin{array}{l}\text { Depth } \\
\text { of } \\
\text { cut (mm) }\end{array}$ \\
\hline 1 & Copper(Cu) & 0.20 & 0.05 \\
\hline 2 & Brass $(\mathrm{Br})$ & 0.25 & 0.08 \\
\hline 3 & Graphite(Gra) & 0.30 & 0.10 \\
\hline
\end{tabular}

A $3^{3}$ full factorial experiment yields 27 experiment runs with no replicates. Table II shows the responses that have been recorded for each run of the experimental design.

\section{B. Measurement System}

Initial hardness of the Ti6Al4V block prior to machining is measured using a hardness testing machine and recorded as $284 \mathrm{HB}$ (brinnel hardness). A hardened steel ball indenter as illustrated in Figure 4 is forced into the workpiece using a specified load $\mathrm{F}$ (here $30 \mathrm{kN}$ ). The dimensions of the impression (actual shown in Figure 5a) are measured using a tool maker's microscope shown in Figure $5 \mathrm{~b}$ and they are substituted into the formula expressed in (1) in order to calculate the brinnel hardness (HB) after each run. The readings are listed in the Table 2.

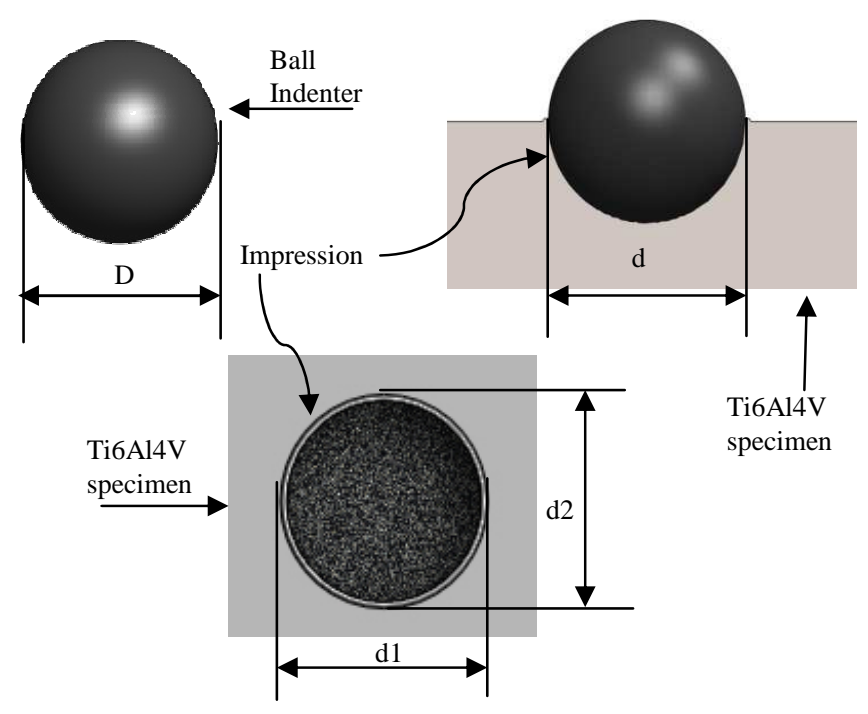

Fig. 4 Brinnel hardness measurement procedure

Formula for calculating the brinnel hardness of the specimen using the dimensions of the impression

$$
\text { Brinnel } H B=\frac{\text { Load }}{\text { Surface }}=\frac{2 F}{\pi D\left[D-\sqrt{\left.D^{2}-d^{2}\right]}\right.}
$$

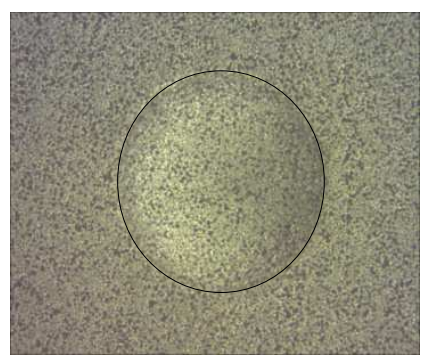

(a)

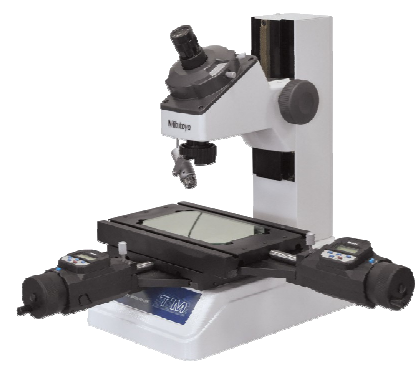

(b)
Fig. 5 (a) Actual impression on the Ti6Al4V specimen; (b) Mitutoyo toolmaker's microscope

The surface roughness at every experiment run is measured using a Mitutoyo surface roughness tester shown in Figure 6 and the $R_{a}$ values in $\mu \mathrm{m}$ are recorded for further statistical analysis in Table 2.

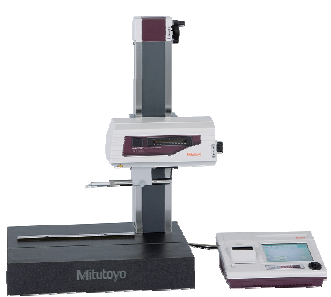

(a)

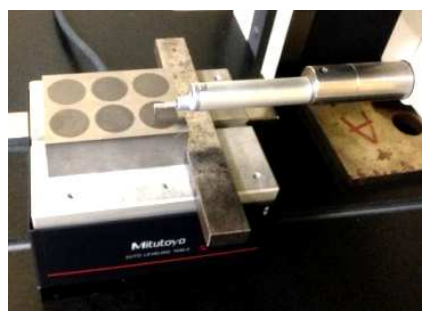

(b)
Fig. 6 (a) Mitutoyo surface roughness tester; (b) actual measurement of machined profiles on Ti6Al4V specimen

To measure the efficiency of the process, the depth of cut is manipulated having three levels as shown in Table 1. The actual depth achieved on the work piece is measured. This is done to identify the electrode material which gives the best result in terms of dimensional accuracy. Here only the depth achieved ( $\mathrm{Z}$ axis dimension) is considered for the study. The diametrical dimension of the profile is intentionally 
neglected due to the reason that in a non-orbital EDM process the end wear of the electrode is greater than the side wear. In an orbital process the electrode wear is even along the sides and the ends [15]. The depth achieved is measured at three points of the profile after each experimental run using a plunger dial depth gauge as shown in Figure 7 and the average of the three readings is recorded. However the response considered here is the dimensional differential (DD).

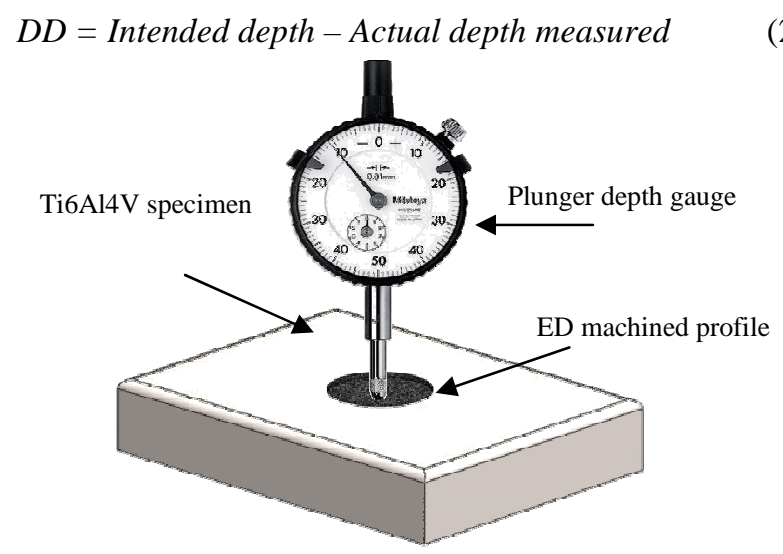

Fig. 7 Depth measurement of the ED machined Profile

TABLE II

EXPERIMENTAL DESIGN (RANDOM ORDER) WITH RESPONSES

\begin{tabular}{|c|c|c|c|c|c|c|}
\hline Exp.no. & EM & SG & DoC & SR & SH & DD \\
\hline 1 & $\mathrm{Cu}$ & 0.25 & 0.08 & 3.671 & 266.111 & 0.05 \\
\hline 2 & $\mathrm{Gra}$ & 0.25 & 0.08 & 2.524 & 316.207 & 0.03 \\
\hline 3 & $\mathrm{Gra}$ & 0.25 & 0.05 & 2.362 & 284.993 & 0.014 \\
\hline 4 & $\mathrm{Br}$ & 0.25 & 0.08 & 4.965 & 316.207 & 0.05 \\
\hline 5 & $\mathrm{Cu}$ & 0.25 & 0.05 & 3.487 & 262.608 & 0.03 \\
\hline 6 & $\mathrm{Br}$ & 0.2 & 0.1 & 5.009 & 305.875 & 0.07 \\
\hline 7 & $\mathrm{Br}$ & 0.25 & 0.05 & 2.841 & 299.838 & 0.02 \\
\hline 8 & $\mathrm{Gra}$ & 0.2 & 0.08 & 5.39 & 294.314 & 0.025 \\
\hline 9 & $\mathrm{Br}$ & 0.2 & 0.08 & 3.081 & 269.379 & 0.046 \\
\hline 10 & $\mathrm{Cu}$ & 0.2 & 0.1 & 3.967 & 294.314 & 0.012 \\
\hline 11 & $\mathrm{Br}$ & 0.3 & 0.05 & 2.642 & 266.11 & 0.025 \\
\hline 12 & $\mathrm{Gra}$ & 0.3 & 0.1 & 5.47 & 304.081 & 0.028 \\
\hline 13 & $\mathrm{Br}$ & 0.3 & 0.08 & 4.955 & 318.487 & 0.002 \\
\hline 14 & $\mathrm{Cu}$ & 0.25 & 0.1 & 4.039 & 329.448 & 0.07 \\
\hline 15 & $\mathrm{Gra}$ & 0.2 & 0.1 & 2.978 & 266.11 & 0.044 \\
\hline 16 & $\mathrm{Gra}$ & 0.25 & 0.1 & 3.212 & 304.081 & 0.05 \\
\hline 17 & $\mathrm{Cu}$ & 0.3 & 0.1 & 3.129 & 294.314 & 0.025 \\
\hline 18 & $\mathrm{Cu}$ & 0.3 & 0.08 & 4.792 & 267.589 & 0.05 \\
\hline 19 & $\mathrm{Br}$ & 0.2 & 0.05 & 2.722 & 270.884 & 0.028 \\
\hline 20 & $\mathrm{Br}$ & 0.25 & 0.1 & 2.712 & 299.838 & 0.07 \\
\hline 21 & $\mathrm{Cu}$ & 0.3 & 0.05 & 2.77 & 298.096 & 0.029 \\
\hline 22 & $\mathrm{Gra}$ & 0.3 & 0.05 & 3.61 & 281.448 & 0.018 \\
\hline 23 & $\mathrm{Br}$ & 0.3 & 0.1 & 4.094 & 298.096 & -0.18 \\
\hline 24 & $\mathrm{Cu}$ & 0.2 & 0.08 & 4.457 & 294.314 & 0.049 \\
\hline 25 & $\mathrm{Gra}$ & 0.2 & 0.05 & 2.053 & 284.993 & 0.009 \\
\hline 26 & $\mathrm{Gra}$ & 0.3 & 0.08 & 7.835 & 327.054 & 0.034 \\
\hline 27 & $\mathrm{Cu}$ & 0.2 & 0.05 & 3.126 & 262.608 & 0.029 \\
\hline & & & & & & \\
\hline
\end{tabular}

(Unit for SG, DoC, DD is $\mathrm{mm}$, unit for SR is $\mu \mathrm{m}$ and unit for SH is HBbrinnel hardness)

\section{RESULTS AND DISCUSSION}

\section{A. Statistical Analysis}

The data recorded is further analysed using statistical software in order to find the significance of the input factors to each of the responses and their correlations. Figure 8 shows the comparison of the surface roughness values between the different electrode materials with the combination order of inputs starting from the minimum level of spark gap and depth $(0.20,0.05)$ in experiment run number 1 to their maximum levels $(0.30,0.10)$ in experiment number 9 show along the $\mathrm{X}$ axis of the plot respectively.

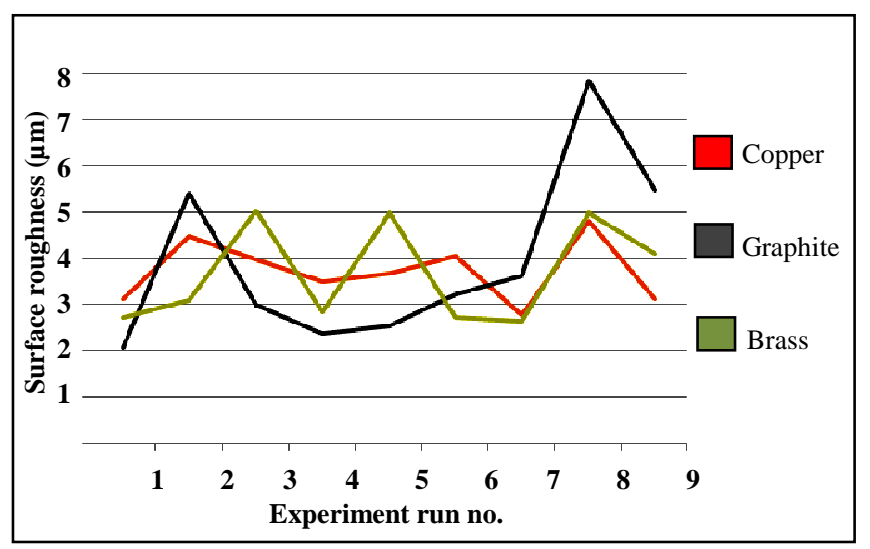

Fig. 8 Surface roughness comparison

The above plot shows that the surface roughness is minimal when machined with lower spark gaps and lower depths (Experiment runs 1,4and 7) for all the three electrode materials with graphite producing the best results. However to ascertain the significance of the three input variables over the surface roughness a regression analysis is carried out and the $\mathrm{P}$ values are derived as shown in Table III.

TABLE III

SIGNIFICANCE OF INPUT VARIABLES TO SURFACE ROUGHNESS

\begin{tabular}{|c|c|}
\hline Predictors & P Values (significance) \\
\hline Electrode material & 0.936 \\
\hline Spark Gap & 0.218 \\
\hline Depth of Cut & 0.054 \\
\hline
\end{tabular}

None of the variables show a significant influence over the surface roughness though the depth of cut shows a bordering significant trend, being just above the threshold of 0.05 . It is inferred that a replication of experiments may yield a more significant result.

A similar statistical analysis carried out on the surface hardness reveals the magnitude of hardness induced or expelled post machining based on the initial hardness measured as shown in Figure 9. The graph shows that surface hardness is indeed influenced upon ED machining regardless of the electrode material that is used. The deviation of points from the initial hardness reference line (dashed blue line) shows an inconsistent pattern in the deviation. Upon performing a regression analysis for the above it is found that the depth of cut is a highly significant factor $(\mathrm{P}=0.021)$ that determines the surface hardness while the electrode material and the spark gap do not impact this property as shown in Table IV. 


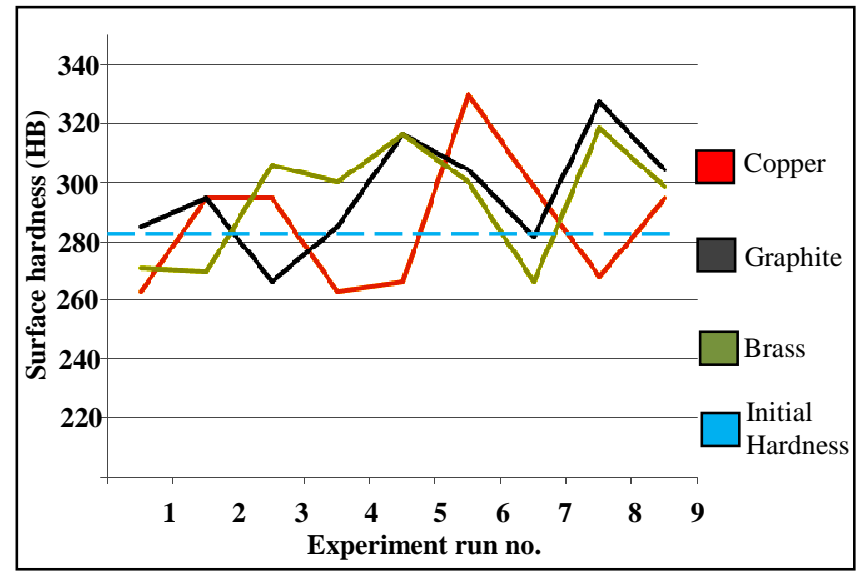

Fig. 9 Surface hardness comparison

TABLE IV

SIGNIFICANCE OF INPUT VARIABLES TO SURFACE HARDNESS

\begin{tabular}{|c|c|}
\hline Predictors & P Values (significance) \\
\hline Electrode material & 0.340 \\
\hline Spark Gap & 0.159 \\
\hline Depth of Cut & 0.021 \\
\hline
\end{tabular}

The final response recorded in this study is the dimensional differential which is the difference in the intended dimension and the actual achieved dimension (depth). The desired dimensional differential is zero. However electrode wear and the electrode material resistivity tend to prevent the achievement of an absolute zero. Figure 10 shows the difference in dimensions.

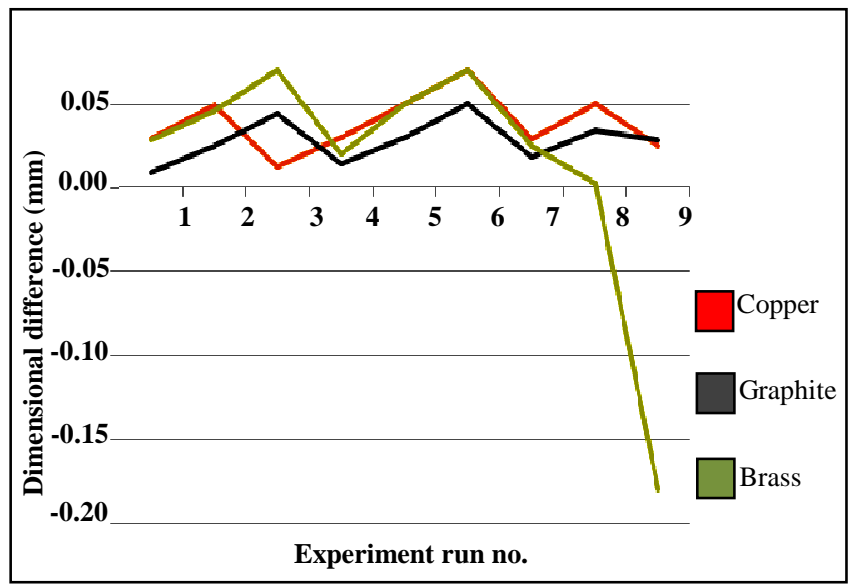

Fig. 10 Dimensional differential Plot

It is observed that graphite electrode is more efficient as the plot is closer to zero when compared to the copper and brass plots. It can be inferred through this observation that graphite electrodes wear off lesser than the other two thus enabling it to achieve a near intended depth. This is due to the fact that graphite electrodes exhibit a higher resistivity towards electricity thus passing minimum spark energy through it. This behavior in turn helps to preserve the end wear of the electrode. A regression analysis conducted on this observation does not attribute the significance to any of the three input variables. Hence it is inferred that the electrical resistivity and the melting points of the electrode materials influence the electrode wear and material removal rate on Ti6Al4V.

TABLE V

SIGNIFICANCE OF INPUT VARIABLES TO DIMENSIONAL DIFFERENCE

\begin{tabular}{|c|c|}
\hline Predictors & P Values (significance) \\
\hline Electrode material & 0.275 \\
\hline Spark Gap & 0.153 \\
\hline Depth of Cut & 0.976 \\
\hline
\end{tabular}

This study on the EDM die sinking operation of Ti6Al4V has derived results favoring graphite as the optimum electrode material. The reason for this could be attributed to the excellent electrical properties of graphite namely its high resistivity $\left(3 \sim 60 \times 10^{-5} \Omega \mathrm{m}\right)$ when compared to the resistivity of copper $\left(1.724 \times 10^{-8} \Omega \mathrm{m}\right)$ and brass $(5.9 \sim 7.1 \times 10-8 \Omega \mathrm{m})$. Higher the resistivity, lesser the spark energy expelled through the electrode thus causing lesser electrode wear off. Due to the lesser spark energy released by graphite, a finer operation produces a smoother surface. Another contributor to this effect is the high melting point of graphite. Graphite does not melt into liquid; instead it sublimes into vapor upon exceeding its melting temperature $5530^{\circ} \mathrm{C}$. This property helps maintain the size of the electrode which in turn helps achieve the near intended depth of cut on the work piece.

It should also be noted that graphite is known for its excellent machinability. However, very fine ribs machined on graphite may snap off during the die sinking process due to heavy flushing of the dielectric regardless of the work piece material. The depth of cut of the operation has been observed to be an important factor that influences the surface hardness which implies that the deeper the profile, longer is the operation time where the surface is exposed to the heat emitted by the spark energy.

\section{CONCLUSIONS}

A miniaturized un-deliberate heat treatment process involving continuous cycles of heating and quenching occurs at the surface creating a hardened surface layer or recast layer. Further study is recommended in this area which focuses more on the electrical properties and also by varying the peak current, pulse width and off-times during machining, which may chart out other significant influencers of Ti6Al4V die sinking process.

\section{REFERENCES}

[1] Manjaiah, M., S. Narendranath, and S. Basavarajappa. "A Review on Machining of Titanium based alloys using EDM and WEDM." Rev. Adv. Mater. Sci 36 (2014): 89-111.

[2] Suresh, S., Moe, A., Che Daud, N., \& Mohd Din, N. "Dimensional Instability caused by Flexural Elastic Modulus in CNC Turning of Titanium Alloy - Ti6Al4v", (n.d.) (2015). (unpublished)

[3] Armendia, M., et al. "Influence of heat treatment on the machinability of titanium alloys." Materials and Manufacturing Processes 27.4 (2012): 457-461.

[4] Zaw, H. M., et al. "Formation of a new EDM electrode material using sintering techniques." Journal of Materials Processing Technology 89 (1999): 182-186.

[5] Hasçalık, Ahmet, and Ulaş Çaydaş. "Electrical discharge machining of titanium alloy (Ti-6Al-4V)." Applied Surface Science 253.22 (2007): 9007-9016. 
[6] Jabbaripour, B., et al. "Investigating the effects of EDM parameters on surface integrity, MRR and TWR in machining of Ti-6Al4V." Machining Science and Technology 16.3 (2012): 419-444.

[7] Strasky, J., M. Janecek, and P. Harcuba. "Electric discharge machining of Ti-6Al-4V alloy for Biomedical Use." WDS. Vol. 11

[8] Khan, Md Ashikur Rahman. "Modelling and Optimization of Performance Characteristics in Electrical Discharge Machining on Titanium Alloy." Journal of Mechanical Engineering43.1 (2013): 3340.

[9] The ASM Aerospace Specification Metals Inc. website. [Online] (2016) Available: http://www.aerospacemetals.com/titanium-ti-6al4v-ams-4911.html

[10] Sen, Indrani, et al. "A study on machinability of B-modified Ti-6Al4V alloys by EDM." Materials and Manufacturing processes 27.3 (2012): 348-354.
[11] Khan, Ahsan Ali. "Electrode wear and material removal rate during EDM of aluminum and mild steel using copper and brass electrodes." The International Journal of Advanced Manufacturing Technology 39.5-6 (2008): 482-487.

[12] Minhat, Ade Erawan Bin, et al. "Model of Pulsed Electrical Discharge Machining (EDM) using RL Circuit." International Journal of Power Electronics and Drive Systems 5.2 (2014): 252

[13] Mitsubishi NC EDM Systems Instruction Manual

[14] Joshi, S. N., and S. S. Pande. "Intelligent process modeling and optimization of die-sinking electric discharge machining." Applied soft computing 11.2 (2011): 2743-2755.

[15] The POCO Graphite, EDM Technical manual website. [Online]. Available: http://edmtechman.com/about.cfm?pg=2\&chap=6

[16] The Engineering Toolbox website. [Online]. Available: http://www.engineeringtoolbox.com/resistivity-conductivityd_418.html 